\title{
Arbeidsduurverkorting in leidinggevende en specialistische functies
}

\author{
Naar een integrale benadering
}

\section{Inleiding}

In de $\mathrm{CAO}$-onderhandelingen van de afgelopen jaren heeft arbeidsduurverkorting (ADV) een zeer centrale rol gespeeld (Nagelkerke, Vogels 1986). In 1983 en 1984 zijn in tal van CAO's afspraken gemaakt over de invoering van de 38-urige werkweek en in sommige zelfs over de 36-urige werkweek (Ministerie van Sociale zaken en Werkgelegenheid, 1984, 1985 (1) en (2), 1986, Loontechnische Dienst, 1986). In 1985 stagneerde dit proces, onder andere doordat in vele organisaties de invoering van ADV problemen opleverde.

Eén van de grootste, alom gesignaleerde knelpunten, betrof de positie van leidinggevenden en specialisten. Vooral deze categorieën bleken in de knel te zijn gekomen door ADV.

Dat was voor het Ministerie van Sociale Zaken en Werkgelegenheid aanleiding om het IVA, Instituut voor sociaal-wetenschappelijk onderzoek, en de Faculteit der Economische Wetenschappen van de Katholieke Universiteit Brabant te verzoeken een onderzoek in te stellen naar de positie van lagere leidinggevenden, middenkader en specialisten met betrekking tot de arbeidsduurverkorting.

Het onderzoek, dat acht case-studies omvatte, moest antwoord geven op de volgende vragen:

- Welke knelpunten ontstaan bij ADV in lager en middelbaar leidinggevende functies en in specialistische functies?

- In hoeverre en op welke wijze slaagt men er in de praktijk in de knelpunten weg te nemen?

- Zijn er meer adequate oplossingen mogelijk voor de bestaande problemen rondom $A D V$ en zijn er mogelijkheden tot verdere ADV in deze functies?

In dit artikel zullen de resultaten van het onderzoek kort worden weergegeven. Daarnaast zullen we stil blijven staan bij mogelijke alternatieve oplossingen voor de door ADV gerezen problemen. In de eerste plaats omdat de ADV weliswaar is doorgevoerd maar er toch geen sprake is van acceptatie. $A D V$ is in vele gevallen nog steeds een van buiten het bedrijf en los van de voorkeuren van individuele betrokkenen opgelegde maatregel. Een dergelijke situatie is op termijn niet stabiel. Ten tweede laten berekeningen ten aanzien van werkloosheid op langere termijn zien dat verdere herverdeling van arbeid in de toekomst waarschijnlijk onvermijdelijk zal zijn. In de derde 
plaats is zeker bij een werkweek van 36 uur voor genoemde functionarissen in vele gevallen een aanpassing van de werkverdeling nodig. Het aandragen van ideeën hiervoor is, zoals ons is gebleken tijdens het onderzoek, nuttig. En in de vierde plaats is de ADV-problematiek verwant aan moeilijkheden die ontstaan door de introductie van niet-standaard werktijdpatronen zoals bijvoorbeeld deeltijdarbeid en tijdelijke arbeidscontracten. Arbeidsorganisaties staan voor de opgave om een steeds grotere variëteit aan werkpatronen te managen.

Vooral gelet op dit laatste punt zullen daarom in de laatste paragraaf conclusies getrokken worden waarbij de problematiek verbreed wordt van de inrichting van de arbeids- en bedrijfstijd naar de inrichting van de arbeidsorganisatie. Allereerst zullen we echter laten zien hoe in onderzoek dat aan ons onderzoek vooraf ging de gevolgen van ADV voor leidinggevenden en specialisten aan de orde gekomen zijn.

\section{Problemen van leidinggevenden en specialisten}

In alle rapporten komt men tot de conclusie, dat als gevolg van ADV de werkbelasting van het lager- en middenkader is toegenomen. Zo wordt bijvoorbeeld bij VMF-Stork geconstateerd, dat de ADV bij chefs en vaklieden het hardst aangekomen is. De verminderde werktijd is in deze onderneming onder meer opgevangen door middel van uitzendarbeid, uitbesteding en overwerk. De zorg daarvoor komt neer op de schouders van deze functionarissen. In een AWV-onderzoek onder bierbrouwerijen werd hetzelfde gevonden. Bovendien bleek het management in deze bedrijfstak vaak in te springen als er gaten vielen.

Andere problemen van het management, en in veel gevallen ook van de specialisten, die steeds weer in de onderzoeksverslagen worden genoemd hebben betrekking op de zorg voor de communicatie, coördinatie en bereikbaarheid (zowel intern als extern).

De taakverzwaring is mede het gevolg van de steeds grotere discrepantie tussen arbeids- en bedrijfstijd. Ook als er geen bedrijfstijdverlenging heeft plaatsgevonden, dan nog is de leidinggevende (door zijn eigen roostervrije dagen) meer dan voorheen afwezig. In sommige bedrijven in de metaal en de elektrotechnische industrie vrezen chefs, dat de produktiviteit op die manier zal dalen bij gebrek aan toezicht (Berenschot, 1985). In verscheidene rapporten wordt in dit verband opgemerkt, dat veel leidinggevenden niet of slechts ten dele aan ADV toekomen. En zo zij wel roostervrije dagen opnemen, dan ontstaat er een overschot aan gewone vrije dagen, die worden doorgeschoven naar volgend jaar waardoor het probleem alleen maar groter wordt.

Bij specialisten doen zich soortgelijke problemen voor. De FNV maakt in dit verband onderscheid tussen functies met veel en functies met weinig autonomie en constateerde, dat het werk van functionarissen met een grote autonomie tijdens hun afwezigheid blijft liggen 'zodat mensen ervoor "kiezen" om nauwelijks vrije dagen of roostervrije dagen op te nemen'.

De kern van het probleem is dat in deze functies niet of nauwelijks herbezetting heeft plaatsgevonden. Er moet evenveel of zelfs meer werk verzet 
worden in minder tijd (De Lange, 1985). De vraag die dan voortdurend wordt gesteld is, of het werk uitwisselbaar is of niet. In het midden- en kleinbedrijf, met name in de kleinere detailhandel, wordt veelal gesteld dat herbezetting niet mogelijk is, doordat de weggevallen capaciteit te gering is. Daardoor moeten de ondernemer zelf en meewerkende gezinsleden harder gaan werken (Elsendoorn, Van Ginneken, 1986). In het onderzoek bij bierbrouwerijen wordt geconcludeerd, dat externe herbezetting niet mogelijk is, omdat door de geringe omvang van afdelingen herbezetting tot overcapaciteit zou leiden en dat interne herbezetting problematisch is doordat veel functies te specialistisch zijn.

Ook Philips laat zich op dit punt negatief uit. Bijna de helft van zijn medewerkers is van mening, dat zijn of haar werk onmogelijk in deeltijd kan worden gedaan. In het rapport van AKzo treffen we eenzelfde beeld aan. Bij specialistische, solistische functies en projectgebonden werk wordt het werk niet overgenomen. Daarbij wordt onder meer gesteld dat herbezetting kwalitatief onvoldoende kan plaatsvinden, omdat de nieuwe medewerkers ervaring en opleiding missen. De Industriebond FNV kijkt daar bij AKzo heel anders tegenaan. Zij stelt dat het argument van de ondeelbaarheid vaak gebruikt wordt om het eigen 'koninkrijkje' te beschermen. In dit verband kan ook verwezen worden naar een al wat oudere studie van de Stichting Stuurgroep Sociaal-Wetenschappelijk Onderzoek. Op grond van onder meer functie-analyse werd daarin vastgesteld dat deeltijdarbeid in vrijwel alle functies organisatorisch te realiseren is (Schoemaker e.a., 1981).

De conclusies die uit de bevindingen getrokken worden zijn zeer verschillend. De sterk door een werkgeversoriëntatie gekleurde onderzoeken komen tot een afwijzen van ADV of op z'n minst tot de wens in ruime mate uitzonderingen te mogen maken. Door (onder andere) Berenschot wordt aangedrongen op scholing en functie-roulatie om daardoor het personeel breder inzetbaar te maken.

Over differentiatie, het op verschillende manieren invullen van ADV binnen één bedrijf of zelfs binnen één afdeling, wordt heel verschillend gedacht. Eén van de vormen die in dit verband veelvuldig genoemd worden is het spaarmodel: het opsparen van roostervrije tijd voor educatief verlof of vervroegd pensioen. Bedrijfsdirecties van Philips bijvoorbeeld waren van mening, dat in $198520 \%$ van de medewerkers van ADV had moeten worden uitgezonderd. Daarnaast vond men dat ook veel meer variatie in de vormgeving had moeten worden aangebracht. Tegelijkertijd werd echter gezegd, dat daarmee inbreuk gemaakt wordt op 'een jarenlang gevoerd beleid gericht op gelijke werktijden van personeel ondanks ongelijke werksituaties'.

Ook in de onderzoeken van de Katholieke Universiteit Brabant (De Lange, 1985), van Berenschot en van AKzo werd geconstateerd, dat differentiatie kan leiden tot spanningen. Paradoxaal genoeg wordt juist in het Industriebond-onderzoek bij AKZO een lans gebroken voor differentiatie. Weliswaar wordt gesteld dat uitzonderingen zoveel mogelijk voorkomen moeten worden, maar als dat de ADV in de weg staat, dan mag niet geschroomd worden om tot een verschillende invulling over te gaan. 
Veel andere oplossingen zijn in de genoemde studies niet aangereikt. Dat is typerend voor de tijd waarin de rapporten zijn verschenen. De ADV verkeerde nog in een beginstadium. Eerst moesten de problemen geïnventariseerd worden. Vervolgens kon meer oplossingsgericht gedacht gaan worden. Dat was één van de uitgangspunten van het genoemde onderzoek van de KUB en het IVA (De Lange, Maas, 1986).

\section{Uitkomsten van het onderzoek}

In de loop van het onderzoek bleek dat de te onderzoeken functiecategorieën een vrij grote differentiatie vertonen.

Daarom zijn de onderzochte leidinggevende functies nader onderverdeeld in vier categorieën:

- strategisch leidinggevenden;

- coördinerend leidinggevenden;

- direct leidinggevenden en

- meewerkend leidinggevenden.

Ten aanzien van de specialistische functionarissen is onderscheid gemaakt tussen diegenen die als solist werkzaam zijn en de specialisten die met meerdere collega's (al of niet in teamverband) min of meer hetzelfde werk doen. In het kader van deze bijdrage zullen wij aan dit laatste onderscheid slechts weinig aandacht besteden, aangezien de verschillen gering dan wel tautologisch bleken te zijn.

In het hiernavolgende geven we een globale typering van de onderzochte functiecategorieën en gaan we in op de ervaringen met ADV.

Bij de typering ligt het accent op die kenmerken die relevant zijn in het licht van ADV. Met name kijken we naar de factoren die de vervangbaarheid en overdraagbaarheid bepalen. Onder vervangbaarheid verstaan we de mate waarin de plaats van een functionaris (tijdelijk) kan worden ingenomen door een of meer andere functionarissen. Onder overdraagbaarheid de mate waarin werkzaamheden van een functionaris kunnen worden overgegeven aan een of meer andere functionarissen. Deze begrippen (ook de term uitwisselbaarheid wordt vaak gebruikt) houden uiteraard verband met elkaar.

Factoren die de vervangbaarheid/overdraagbaarheid in belangrijke mate bepalen zijn (cfr. Markensteyn c.s., 1983):

- de aard van de taak (aandeel van leidinggevende, algemeen uitvoerende, specifiek uitvoerende en beleidsmatige taken);

- het (eventuele) kwantitatieve aandeel in het uitvoerend werk op de afdeling;

- de cyclus: op welke termijn moeten telkens zaken worden afgerond, c.q. hoe sterk is de mate van toezicht;

- de specificiteit: de vereiste kwalificaties wat aard en niveau betreft inclusief de minimaal benodigde bedrijfservaring;

- de uniciteit: de mate waarin de functie 'uniek' is binnen de afdeling/het bedrijf. 
Voor elke onderzochte functie is op basis van de interviews een inschatting gemaakt van de 'score' op deze factoren. Dat is gedaan voor de verschillende onderdelen waaruit de functie kan bestaan: leiding geven, algemeen uitvoerend werk (hetzelfde werk doen als anderen op de afdeling), specifiek uitvoerend werk en beleidswerk. (Voor een deel zit de uitslag van deze score uiteraard al opgesloten in de afbakening van de functiecategorieën.)

Kortheidshalve worden de leidinggevende functies in schema 1 naar de onderscheiden kenmerken getypeerd. De typering is gebaseerd op de onderzoeksresultaten.

Schema 1: Factoren die de uitwisselbaarheid bepalen in leidinggevende functiecategorieën

\begin{tabular}{rcl}
$\begin{array}{l}\text { meewerkend } \\
\text { leidinggevenden }\end{array}$ & $\begin{array}{l}\text { direct } \\
\text { leidinggevenden }\end{array} \quad \begin{array}{l}\text { coördinerend } \\
\text { leidinggevenden }\end{array}$ & $\begin{array}{l}\text { strategisch } \\
\text { leidinggevenden }\end{array}$ \\
\hline weinig & $\leftarrow$ beleidsmatig werk $\rightarrow$ & veel \\
veel & $\leftarrow$ uitvoerend werk $\rightarrow$ & weinig \\
kort & $\leftarrow$ cyclus $\rightarrow$ & lang \\
klein & $\leftarrow$ specificiteit $\rightarrow$ & groot \\
werkeenheid & $\leftarrow$ niveau van uniciteit $\rightarrow$ & organisatie \\
\hline
\end{tabular}

De onderzochte specialistische functies zijn wat de aard van het werk, cyclus, koppeling aan andere functies en specificiteit betreft zeer gevarieerd. Zowel lagere functies met naar verhouding veel algemeen uitvoerend werk, als hogere functies met een zeer specifieke inhoud kunnen onder deze categorie gerangschikt worden. Het belangrijkste onderscheidende criterium is de mate van uniciteit, welk kenmerk ook al in de genoemde afbakening (solisten en specialisten) tot uiting komt. Solisten zijn in hoge mate uniek binnen de organisatie, overige specialisten niet.

Op soortgelijke wijze als in schema 1 kan nu vervolgens het beeld met betrekking tot de ADV voor de leidinggevende functiecategorieën worden weergegeven.

Schema 2: Aspecten van arbeidsduurverkorting bij leidinggevende functiecategorieën

\begin{tabular}{|c|c|c|c|}
\hline $\begin{array}{l}\text { meewerkend } \\
\text { leidinggevenden }\end{array}$ & $\begin{array}{l}\text { direct } \\
\text { leidinggevenden }\end{array}$ & $\begin{array}{l}\text { coördinerend } \\
\text { leidinggevenden }\end{array}$ & $\begin{array}{l}\text { strategisch } \\
\text { leidinggevenden }\end{array}$ \\
\hline groot & \multicolumn{2}{|c|}{$\leftarrow$ noodzaak tot opvang $\rightarrow$} & gering \\
\hline groot & \multicolumn{2}{|c|}{$\leftarrow$ mogelijkheden voor opvang $\rightarrow$} & gering \\
\hline meestal wel & \multicolumn{2}{|c|}{$\leftarrow$ feitelijke opvang $\rightarrow$} & zelden \\
\hline beperkt & \multicolumn{2}{|c|}{$\leftarrow$ stijging werkbelasting $\rightarrow$} & groot \\
\hline meestal wel & \multicolumn{2}{|c|}{$\leftarrow$ opnemen ADV $\rightarrow$} & beperkt \\
\hline gering & \multicolumn{2}{|c|}{$\rightarrow$ vrijheid bij invulling ADV $\rightarrow$} & groot \\
\hline
\end{tabular}

De verschillende aspecten hangen nauw met elkaar samen. Het is een 
gelukkige omstandigheid, dat waar de noodzaak tot snelle vervanging het grootst is (op de laagste leidinggevende niveaus) de mogelijkheden hiertoe ook het grootst zijn. De grote noodzaak leidt er evenzeer toe dat opvang ook daadwerkelijk plaatsvindt.

Hoe hoger men in de organisatie komt, des te minder is er sprake van één of andere vorm van herbezetting. $\mathrm{Nu}$ is er op elk niveau van directe herbezetting nauwelijks sprake. Maar herbezetting kan ook indirect geschieden, dat wil zeggen in de organisatie, doordat taken worden gedelegeerd c.q. vervanging wordt geregeld. Dit laatste komt meer voor naarmate het leidinggevende niveau lager is. En naarmate de opvang beter geregeld is, blijft de stijging van de werkdruk meer binnen aanvaardbare grenzen.

Geconcludeerd kan worden dat de meeste van de in paragraaf 1 en 2 genoemde problemen bij leidinggevenden in dit onderzoek eveneens naar voren komen. Het beeld is evenwel genuanceerder, omdat er een onderscheid wordt gemaakt in verschillende categorieën. Verder blijkt ook hier de herbezetting een sleutelrol te spelen. Van belang is de bevinding dat herbezetting (voor een deel) indirect kan plaatsvinden door delegatie van taken c.q. regelen van vervanging.

Het beeld met betrekking tot $A D V$ is ook bij specialisten genuanceerd.

Wat de noodzaak tot opvang bij afwezigheid betreft laat het onderzoek zien dat dit bij solistische functionarissen heel verschillend ligt. De overige specialisten kunnen over het algemeen zonder problemen enkele dagen gemist worden.

Bij het grootste deel van geïnterviewde specialisten is de ADV ingeroosterd. De meesten nemen de ADV ook op.

Evenals bij de leidinggevenden is er bij deze functionarissen geen sprake van rechtstreekse herbezetting. Bij de solisten vindt bij afwezigheid ook geen vervanging of overdracht plaats, bij de overige specialisten in de helft van de gevallen wel.

De solisten signaleren dan ook in grotere mate dan de overige specialisten een stijging van de werkbelasting. Vooral deze groep ziet zich als gevolg van de ADV gedwongen dezelfde hoeveelheid werk in minder tijd uit te voeren.

Voor alle onderzochte functies geldt dat ADV in de praktijk meestal neerkomt op een of enkele dagen van afwezigheid. Dit geeft problemen in de volgende vijf situaties:

a Het werk wordt direct bepaald door de klant en die klant doet steeds zaken met één bepaalde functionaris. Omdat collega's over het algemeen wel beschikken over de benodigde kennis van het produkt, kunnen routinezaken bij afwezigheid van één dag meestal wel opgevangen worden. Deze situatie komt vooral voor bij specialisten.

$b$ Het werk vormt een substantieel deel van de totale hoeveelheid werk van de afdeling en de cyclus is korter dan één dag. Dit geldt vooral voor meewerkend leidinggevenden en in mindere mate voor direct leidinggevenden.

c Het werk is nooit af. In een aantal van de onderzochte functies bepaalt 
de betrokkene zelf de input (tijd en energie), terwijl de output door anderen beoordeeld wordt. De ervaring is dat men zelf opdraait voor het nemen van een vrije dag, het werk blijft liggen. Bij de beoordeling wordt echter geen rekening gehouden met ADV. Deze situatie is vaak kenmerkend voor strategisch en coördinerend leidinggevenden en voor specialisten.

d Het werk is (te) omvangrijk en er is niet of nauwelijks overdracht mogelijk. Dit geldt voor solisten en in mindere mate voor direct en coördinerend leidinggevenden.

e Het werk eist bijna continue aanwezigheid. Dit komt voor in situaties waarin er iemand moet zijn die permanent toezicht houdt of opdrachten geeft. Deze situatie geldt voor een aantal meewerkend en direct leidinggevenden.

Zoals eerder aangegeven laat dit onderzoek vooral zien dat de problematiek gedifferentieerd ligt voor de verschillende typen functies.

Er zijn diverse wegen waarlangs de genoemde knelpunten kunnen worden weggenomen. Voor een deel zijn deze in de praktijk al gerealiseerd. Bij het uitblijven van directe herbezetting (de meest voor de hand liggende, maar weinig toegepaste oplossing) had men de keuze uit de volgende mogelijkheden:

- werk laten liggen;

- dezelfde hoeveelheid werk doen in minder tijd;

- dezelfde hoeveelheid werk doen in dezelfde tijd (dus niet opnemen van ADV);

- werk overdragen.

De eerstgenoemde mogelijkheid wordt door de betrokken functionarissen meestal niet eens overwogen: van vermindering van de kwaliteit van dienstverlening kan in deze functies geen sprake zijn. Bovendien weet men dat schuiven met werk alleen op korte termijn soelaas biedt.

Het tweede en derde alternatief (vaak gekozen door de betrokkenen) zijn te plaatsen op de noemer 'flexibele opstelling van de werknemer', een zeer typerende houding voor leidinggevenden en specialisten. De consequenties van deze werknemersflexibiliteit - stijging van de werkbelasting, het niet of onvolledig opnemen van ADV-dagen - heeft men (voorlopig) voor lief genomen. Het is echter duidelijk dat er wat dit betreft snel grenzen worden bereikt.

Resteert als meest interessante alternatief overdracht van taken c.q. organiseren van vervanging. De cases laten daar een aantal voorbeelden van zien.

- In een van de onderzochte organisaties (een bank) is een afdeling onderzocht waar onder meer accountmanagers werken (een specialistische functie). Op deze afdeling staat cliëntbediening centraal, veel relaties zijn persoonsgebonden. Omdat de accountmanagers vaak buitenshuis zijn, brengt ADV problemen met zich mee rond communicatie en bereikbaarheid. Op deze afdeling is men daarom bezig duo's te 
kweken (1e en 2e accountmanagers) die elkaars werk gemakkelijk kunnen overnemen.

- In een andere organisatie (een voedingsbedrijf waar het personeel $4 \times 9$ uur per week werkt en de bedrijfstijd $5 \times 9$ uur bedraagt) is rechtstreeks als gevolg van de ADV een roulerend afdelingschef aangesteld. Op elk van de vier dagen waarop deze chef werkt, vervangt hij een chef die dan zijn wekelijkse 'ADV-dag' heeft.

- Bij twee onderzochte organisaties (een rijksdienst en een ziekenhuis) wordt mede als gevolg van ADV gezocht naar mogelijkheden tot delegatie van deeltaken. Op elk leidinggevend niveau trachten leidinggevenden bepaalde werkzaamheden (zoals operationeel leiding geven, administratie, uitvoerend werk) over te dragen aan anderen.

De cases laten echter ook zien dat er nog veel onbenutte mogelijkheden zijn tot opvang bij afwezigheid, zeker op wat langere termijn. Soms spelen daarbij functiekenmerken een rol (persoonsgebonden contacten bijvoorbeeld), soms is het een kwestie van houding van de betrokkenen (niet willen delegeren), vaak echter vormt de organisatie van het werk het knelpunt. Oplossingen moeten dan ook vooral hierin worden gezocht.

\section{Alternatieve oplossingen}

ADV heeft, naast de directe gevolgen, heel wat losgemaakt in organisaties. Een gevolg dat structureel lijkt te zijn is dat de vormgeving van het werk in een veel bredere kring van werknemers in de organisatie ter discussie is komen te staan. In de eerste plaats geldt dit voor de werktijden: wie kan op welk moment gemist worden, wie bepaalt dat en in hoeverre mogen persoonlijke voorkeuren hierin een rol spelen?

Op de tweede plaats zullen de werkverdeling en daarmee de arbeidsorganisatie veranderen, mede als gevolg van het steeds meer uiteenlopen van arbeidstijd en bedrijfstijd. Door taken over te dragen, tijdelijk te laten overnemen, uit te stellen of van tevoren te verrichten is ADV beter te realiseren. En wie heeft hier beter zicht op dan de betrokkene zelf?

Als gevolg van het aandragen van 'goede redenen' door betrokkenen is, ondanks pogingen van zowel management als werknemers(-vertegenwoordigers) om 'gelijkheid' te realiseren, de uniformiteit in de ADV-vormgeving in veel organisaties doorbroken. In een aantal gevallen is dit formeel, in een groter aantal informeel, gepaard gegaan met een decentralisatie van de beslissingen over de invulling van de ADV.

De vormgeving aan het werk is zo een onderwerp geworden dat, veel meer dan voorheen, een plaats heeft in het krachtenveld tussen management en werknemers. De werktijd en daarmee tot op zekere hoogte ook de arbeidsorganisatie, is meer onderhandelbaar geworden. Dit biedt aanknopingspunten voor een integrale benadering: een benadering, waarbij ADV niet als een op zichzelf staand feit gezien wordt, maar als een ontwikkeling die gerelateerd wordt aan andere bedrijfsontwikkelingen. 
$A D V$ is het best in de organisatie geïntegreerd, daar waar zowel management als werknemers baten incasseren. De huidige stagnatie in de voortgang van ADV lijkt vooral het gevolg van een afnemende meeropbrengst voor beide partijen.

Zo was er na het Stichtingsakkoord uit 1982 sprake van een afruil tussen enerzijds de leegloop in organisaties en anderzijds vrije tijd en behoud van werkgelegenheid. Voor veel bedrijven is het leegloopprobleem niet meer actueel. Dit is een gevolg van de gerealiseerde ADV en de stijgende omzetten sinds het herstel van de economie. Het management heeft derhalve in vele gevallen geen baat meer bij ADV als instrument om de overbodige rek uit de organisatie te halen. Voor de werknemers werd het werkdrukprobleem nijpender en bleek de herbezetting tegen te vallen.

In deze situatie is het geen wonder dat de animo voor (verdergaande) ADV verdampt. Op dit moment wordt geprobeerd een ander managementbelang naar voren te schuiven, namelijk flexibilisering (van werktijden) en bedrijfstijdverlenging. Uit de cases blijkt dat inderdaad hierdoor in een aantal gevallen de mogelijkheid ontstaat tot een voor beide partijen acceptabele $\mathrm{ADV}$-vormgeving, of zelfs tot verdergaande ADV. Het probleem is echter dat dit management-belang onvoldoende algemeen is: de behoefte aan flexibiliteit en bedrijfstijdverlenging is lang niet overal aanwezig en het managen ervan vergt nogal wat creativiteit. De algemene koppeling tussen ADV en rendementsherstel lijkt dan ook niet vervangen te kunnen worden door een even algemene koppeling tussen ADV en flexibilisering en/of bedrijfstijdverlenging. Ook met betrekking tot de managementbaten van ADV zal de uniformiteit doorbroken moeten worden.

In de huidige markt- en technologische ontwikkelingen zijn er echter meer koppelingsmogelijkheden voorhanden. In de praktijk hebben sommige organisaties die alternatieven, deels veel verdergaand dan de regeling van de werktijden, al gevonden.

In ons onderzoek is dat bij twee organisaties het geval. In de eerste plaats betreft dit de toenemende behoefte aan scholing en in de tweede plaats de behoefte aan een ingrijpende verandering van de bestaande arbeidsorganisatie. In beide gevallen wordt arbeid (weer) beschouwd als 'human capital' dat zo breed mogelijk moet worden benut.

In de komende jaren zal de behoefte aan scholing voor vooral leidinggevenden en specialisten sterk toenemen. Van de werknemers in het jaar 2000 neemt nu al $75-80 \%$ deel aan het arbeidsproces, terwijl $2 / 3$ van de dan beschikbare technologie nog ontwikkeld moet worden (Zegveld, Enzing, 1986). Nu reeds zittende werknemers zullen deze ontwikkeling dus grotendeels moeten dragen. Daarbij komt dat de effectiviteit en efficiency van indirecte arbeid een steeds belangrijkere rol zal gaan vervullen in het succes van de organisatie. Naast de ontwikkeling van (nieuwe) markten en produkten worden produktieprocessen en organisatiestructuren steeds belangrijker concurrentiemiddelen. Tevens zal, volgens sommige auteurs, door technologische en organisatorische veranderingen het kwantitatieve en kwalitatieve belang van het zogenaamde middenkader in de toekomst waarschijnlijk afnemen. ${ }^{1}$ Deze drie tendensen zullen het werk van leidinggeven- 
den en specialisten ingrijpend veranderen, waardoor scholing noodzakelijk wordt. De noodzaak van scholing geldt voor beide partijen: voor de organisatie om het concurrentievermogen te behouden of te vergroten, voor leidinggevenden en specialisten om hun positie (op de in- en externe arbeidsmarkt) te behouden of te vergroten.

De organisaties die de koppeling hebben gelegd tussen ADV en scholing zijn nog niet talrijk. Het probleem is natuurlijk dat het niet onomstreden is dat werknemers eigen tijd inzetten voor scholing ten behoeve van de organisatie, en ook dat voor scholing zogenaamde spaarvarianten van ADV nodig zijn. Uit de cases blijkt dat spaarvarianten van ADV vrijwel alleen positief worden beoordeeld door oudere werknemers die door de gespaarde ADV hun pensioenleeftijd willen verlagen.

Wat varianten waarin de gespaarde ADV tijdens de loopbaan wordt opgenomen betreft, is de animo van managementzijde niet hoog; er is dan echt herbezetting nodig. Van werknemerszijde is er de angst om door de langere afwezigheid de met zorg opgebouwde positie te verliezen. Tot nu toe worden spaarvarianten gezien als een noodoplossing (Sprangers, 1986).

Bij één van de onderzochte bedrijven, een bank, heeft men de scholingsbehoefte die is ontstaan door veranderingen in de inhoud van het werk inderdaad aangegrepen om vorm te geven aan de ADV. De mogelijkheid is geschapen om de ADV-dagen te benutten voor scholing, het volgen van cursussen, waarbij de werkgever een 'beloning' geeft in de vorm van extra dagen. Deelname aan deze regeling is vrijwillig. De belangstelling voor deze invulling van ADV is vooral groot onder relatief jonge werknemers.

Ook in andere cases lijkt deze vorm aantrekkelijk. Ze komt namelijk ook voor een deel tegemoet aan de klacht, juist bij de door ons onderzochte groepen werknemers, dat men niet toekomt aan het bijhouden van vakliteratuur of het anderszins op de hoogte blijven van ontwikkelingen op het vakgebied. Invulling van de ADV op deze wijze vergt wel een compensatie. In één van de organisaties is dit niet gebeurd: van hogere functionarissen wordt verwacht dat het volgen van cursussen en het bezoeken van congressen of beurzen, wat vroeger 'in de baas zijn tijd' gebeurde in het vervolg op ADV-dagen wordt gedaan. Deze vormgeving kan beter worden omschreven als het uitsluiten van deze groepen van ADV. Overigens maakt deze organisatie zeer goed duidelijk dat de ingeschatte problemen van afwezigheid van functionarissen sterk samenhangen met het doel van de afwezigheid. Afwezigheid wegens het volgen van bijvoorbeeld een managementcursus van een week wordt zonder morren opgevangen. Men kan geen enkel nadelig gevolg bedenken. Afwezigheid van degenen die wel ADV opnemen wordt daarentegen regelmatig wel als een probleem beschouwd.

Op het moment dat scholing gewoon bij werk hoort en is gekoppeld aan ADV zullen afwezigheidsproblemen naar verwachting al sterk afnemen. De noodzaak van scholing kan op deze wijze een doorbraak gaan betekenen in de discussie over de verkorting van de arbeidsduur.

Het tweede alternatief dat we willen noemen past in de discussie rondom de 'nieuwe produktiefilosofie' die sinds de publikatie van Kern en Schumanns 'Das Ende der Arbeitsteilung?' is ontstaan. De 'nieuwe produktie- 
filosofieën' zijn een reactie op de rigiditeit van het Taylorisme, waarvan een scheiding tussen regelende en uitvoerende taken en een verdere opsplitsing van die regelende en uitvoerende taken belangrijke kenmerken zijn (Brödner, 1986). Nieuwe produktiefilosofieën behelzen, naast andere zaken, steeds het terugdringen van deze ontwikkeling.

Een ingrijpend plan uit dit genre hebben we aangetroffen in eén van de cases. Alhoewel flexibilisering bij dit bedrijf voorop staat wil men toch iets anders dan met mensen schuiven al naargelang de behoefte.

Door een integrale verandering van de arbeidsorganisatie via het werken met multi-inzetbare groepen werknemers die groepstaken vervullen en door een verregaande decentralisatie van beslissingsbevoegdheden wil men trachten de werknemers dusdanig bij het bedrijf te betrekken dat de benodigde flexibiliteit autonoom ontstaat. Men verwacht weinig van management-flexibiliteit (het schuiven met mensen door het management als daar behoefte aan bestaat) en wil via werknemers-flexibiliteit (het op eigen inzet van werknemers gebaseerde aanpassingsvermogen) de benodigde flexibiliteit realiseren. De nadruk in het management van de arbeid moet dan verschuiven van het toezicht houden, controleren en plannen van werk naar het scheppen van voorwaarden waaronder de groep zo goed mogelijk functioneert. De groepen zijn in dit ideaalplaatje zelfregelende eenheden, ook als het gaat om de regeling van de werktijden: vakantie, snipperdagen en ADV. De oplossing van de ADV-problematiek wordt hier gevonden door de beslissingen over te laten aan de betrokkenen. Het bedrijf wil graag voor deze ontwikkeling betalen door niet alleen de gemiddelde arbeidstijd van de werknemers te verkorten, maar ook nog de kosten hiervan (inclusief de prijscompensatie) voor zijn rekening te nemen.

Niet voor elke organisatie is een dergelijke drastische ingreep realiseerbaar en evenmin wenselijk. In ieder geval zal ADV op zichzelf onvoldoende reden zijn om de organisatie op haar kop te zetten. Daarbij komt nog dat de beoogde 'job-cultuur' ook een aantal belemmeringen opwerpt tegen ADV: door de grotere druk om zich te conformeren aan het bedrijfsbelang kan de ADV erbij inschieten. Vooral bij leidinggevenden en specialisten wordt, zoals we in paragraaf 3 zagen, deze situatie vrij veelvuldig aangetroffen.

Onmiskenbaar geeft een dergelijke organisatiewijze veel mogelijkheden om een grotere variëteit aan werktijdpatronen te realiseren. Overdracht binnen een groep van breed inzetbare werknemers is immers goed mogelijk en het organiseren daarvan kan aan de groepsleden worden overgelaten. Ook afwezigheid wegens ziekte, vakantie of scholing is beter op te vangen. De rol van leidinggevenden en ook specialisten verandert in een dergelijke organisatie. Men zal veel meer ondersteunend en adviserend bezig zijn, waardoor de continue aanwezigheid veel minder urgent is. Een flexibele organisatie betekent in dit verband dat afwezigheid van één of enkele werknemers niet leidt tot verstoringen in het produktieproces. Een situatie die wordt bereikt niet door het werk zo uit te kleden dat iedereen het kan doen, maar door groepen te vormen die hun eigen werk voor een groot deel zelf organiseren.

Over de kans dat de nieuwe produktiefilosofieën inderdaad breed zullen 
worden doorgevoerd verschillen de meningen. Duidelijk is dat ADV hierbij geen hoofdrol speelt: ADV is slechts één van de 'storingen' die organisaties prikkelen om na te denken over de organisatie van het werk. Er zijn echter meer prikkels nodig dan alleen ADV. Uit het onderzoek blijkt namelijk dat de stap naar een 38-urige werkweek door veel bedrijven binnen de bestaande organisatie is opgevangen. De problemen die ontstaan zijn door de ADV heeft men proberen op te lossen zonder de bestaande organisatie te willen veranderen. Dit is niet in alle gevallen succesvol verlopen. Daarom kan het mede organiseren van ADV door middel van de integrale benaderingswijze een aantrekkelijk alternatief zijn.

\section{Literatuur}

1 AKZO Nederland, Industrie- en voedingsbond CNV, Vereniging van Hoger Personeel bij AKZO, Unie BLHP, Op zoek naar mogelijkheden tot herverdeling van arbeid bij AKZO Nederland, Arnhem, 1986.

2 Algemene Werkgevers Vereniging, Zorgen tot aan het drinkmoment, Haarlem, 1985.

3 Berenschot, Arbeidstijduerkorting en andere werkgelegenheidsverruimende maatregelen in de metaal-en elektrotechnische industrie, Utrecht, 1985.

4 Brödner, P., Fabrik 2000, Alternative Entwicklungspfade in die Zukunft der Fabrik, Berlijn, 1986.

5 Elsendoorn, G., Ginneken, C. van, ATV in kleine bedrijven, Deel I, Evaluatie van de gevolgen, Zoetermeer, 1986.

6 FNV, Arbeidstijdverkorting in de praktīk, Amsterdam, 1986, pag. 54.

7 Fruijtier, B., Het einde van de humanisering? Tijdschrift voor Arbeidsuraagstukken, jrg. 2 , nr. 4.

8 Industriebond FNV, Waar een wil is, is een weg, Amsterdam, 1986.

9 Kern, H., Schumann, Das Ende der Arbeidsteilung?, München, 1984.

10 Lange, W. de, Arbeidstijdverkorting, hoe nu verder?, Tilburg, 1985.

11 Lange, W. de, Maas, A., Arbeidstijdverkorting voor leidinggevende en specialistische functionarissen, 's-Gravenhage, 1986.

12 Loontechnische Dienst, Arbeidsduurverkorting in de periode november 1982 tot en met april 1985, 's-Gravenhage, 1986.

13 Markensteyn, L. e.a., Het werk verdeeld, 's-Gravenhage, 1983.

14 Ministerie van Sociale Zaken en Werkgelegenheid, Rapportage Arbeidsmarkt, 1984, 1985 (1) en 1986.

15 Ministerie van Sociale Zaken en Werkgelegenheid, Rapportage fase 1 van het project Herverdeling van werk, 's-Gravenhage, 1985 (2).

16 Nagelkerke, A., Vogels, E., Drie jaar na het Stichtingsakkoord, $M A B$, februari 1986.

17 Nederlandse Philips Bedrijven B.V., Arbeidsduurverkorting bij Philips in Nederland, Eindhoven, 1985.

18 Rutten, L., Arbeidstijdverkorting bij VMF-Stork; het concern op stelten?, Amsterdam, 1986.

19 Schoemaker, N., Gageldonk, A. van, Demenint, A., Vianen, A. van, Deeltijdarbeid in het bedrijf, Alphen aan den Rijn, 1981.

20 Sprangers, C., met ATV naar de Stille Zuidzee, Intermediair, jrg, 22, 17 januari 1986.

21 VNP, Studie naar eventuele verdergaande arbeidsduurverkorting in de Nederlandse papier-en kartonindustrie, 1985.

22 Zegveld, W., Enzing, Chr., Nieuwe issues in het wetenschaps-en technologiedebat, Delft, 1986.

Noot

1 Op het in oktober 1986 gehouden international congres 'Produktivität und die Zukunft der Arbeit' stonden deze ontwikkelingen centraal en bestond er een opvallende overeenkomst tussen Europese, Amerikaanse en Japanse meningen. 